\title{
Association of health literacy and self-management practices and psychological factor among patients with type 2 diabetes mellitus in Saudi Arabia
}

\author{
Turky H. Almigbal, SBFM, ABFM, Khalid M. Almutairi, MSc, PhD, Jason M. Vinluan, BSN, RN, \\ Mohammed A. Batais, SBFM, ABFM, Abdulaziz Alodhayani, MD, MRCGP, Wadi B. Alonazi, HIA, PhD, \\ Eman Sheshah, MBBS, Razan I. Alhoqail, MBBS.
}

\begin{abstract}

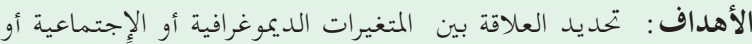

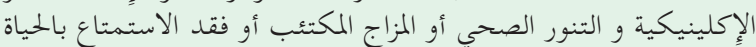

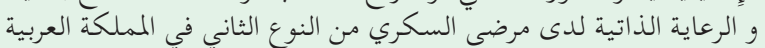
السعودية.

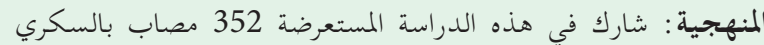

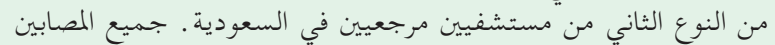

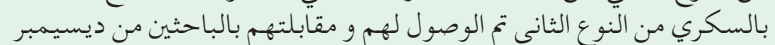

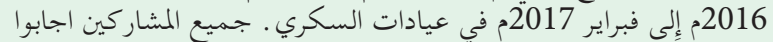

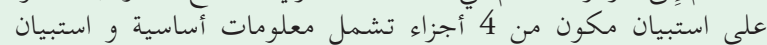

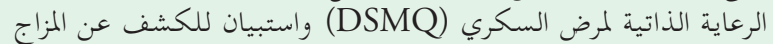

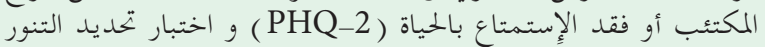

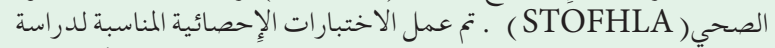

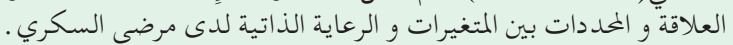

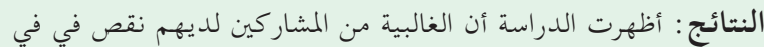

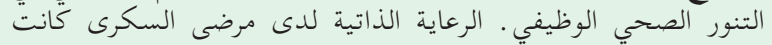

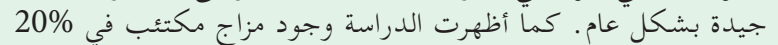

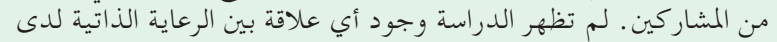

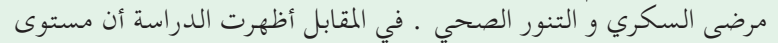

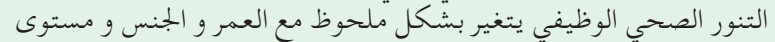

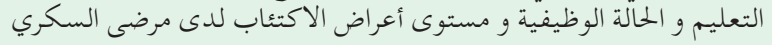

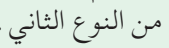

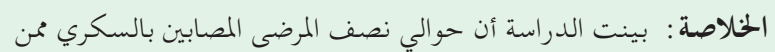

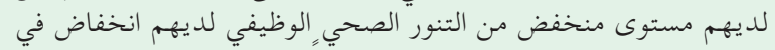

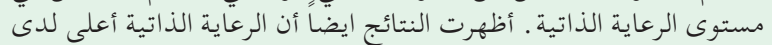

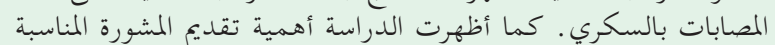

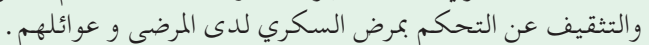

Objectives: To determine the association between sociodemographic, clinical, and health literacy and the presence of depressed mood and their relationships to diabetes self-management among type 2 diabetes mellitus (T2DM) patients in Saudi Arabia.

Methods: A total of 352 T2DM patients from 2 public tertiary hospitals in Saudi Arabia participated in this descriptive cross-sectional study between December
2016 and February 2017. All respondents answered a 4-part questionnaire, which includes demographic data, Diabetes Self-Management Questionnaire (DSMQ), 36item test based Short Test of Functional Health Literacy in Adults, and a 2-item Patient Health Questionnaire (PHQ-2). The Chi-square test and logistic regression analysis were conducted to determine the relationship and significant predictors for self-management among T2DM patients.

Results: The analysis showed that majority of the participants had low to marginal functional health literacy. The overall DSM-16 score was good, indicating more effective self-care, while $20 \%$ of the participants had a score of 2 or more in the PHQ-2 indicating presence of depressed mood. No significant association was found between DSM and health literacy among the study participants while age, gender, educational level, employment status, and level of the depressive symptom were significantly associated with differences in the level of functional literacy of the participants.

Conclusion: The study shows that nearly half of the T2DM patients that exhibited low level of functional health literacy had low diabetes self-management. Our findings also show that gender significantly affects diabetes self-management in which odds are a lot higher among females than males with diabetes selfmanagement. This study underscores the importance of proper counselling and education about diabetes control on both patients and family members.

Saudi Med J 2019; Vol. 40 (11): 1158-1166 doi: 10.15537/smj.2019.11.24585

From the Department of Medicine (Almigbal, Batais, Alhoqail), Department of Community Health Science, College of Applied Medical Science (Almutairi, Vinluan), Department of Family and Community Medicine (Alodhayani), College of Medicine; from the College of Business Administration (Alonazi); and from the Department of Diabetes Center (Sheshah), King Salman Hospital, King Saud University, Riyadh, Kingdom of Saudi Arabia.

Received 28th May 2019. Accepted 17th September 2019.

Address correspondence and reprint request to: Jason M. Vinluan, Department of Community Health Science, College of Applied Medical Science, King Saud University, Riyadh, Kingdom of Saudi Arabia. E-mail: jvinluan.c@ksu.edu.sa

ORCID ID: https://orcid.org/0000-0001-8670-3580 
$\mathrm{D}$ iabetes mellitus is becoming a widespread health problem globally. The prevalence of diabetes is rapidly increasing, adding urgency to research addressing the underlying factors (namely, obesity, unhealthy eating, and sedentary lifestyle). It is estimated that diabetes will increase by $55 \%$ by $2035 .{ }^{1}$ Type 2 diabetes mellitus (T2DM) is the most common type of diabetes, accounting for more than $90 \%$ of total cases. ${ }^{2}$ Patients with T2DM must engage in continuous and specific health management recommendations for the rest of their lives. Long-term health care for T2DM patients involves greater engagement by patients in numerous actions, such as diet, exercise, and medication management in their daily lives. Self-care management practices of diabetic patients have become a major aspect of diabetes care around the world. In the United States, studies show that less than 50\% of patients follow the recommended diabetes management guidelines. ${ }^{3,4}$ Meanwhile, studies in China found that diabetic patients who had low income and educational levels tend to have higher glucose levels, while patients who received diabetic education scored significantly higher on self-care management., ${ }^{5,6}$ Diabetes selfmanagement is considered crucial for satisfactory diabetes control among patients with diabetes. ${ }^{7}$ When patients self-manage adequately, they can decrease the level of glycated hemoglobin by $37 \% .{ }^{8}$ Even with an increase in the evidence supporting the benefit of diabetes self-management, the utilization of selfmanagement actions is still low. ${ }^{9}$ Psychosocial factors such as health literacy and depression can affect diabetes self-management among patients with diabetes. Another complication that might disempower diabetic patients to self-management is reduced psychological wellbeing. ${ }^{10}$ Anxiety, depression, and psychological distress are associated with adverse outcomes, such as lower self-care, which might lead to patients' poorer health status and could further affect and reduce diabetes self-management. ${ }^{11,12}$ If diabetic patients are exposed to tremendous psychological stress, self-care activities may compromise resulting to increased risk of many complications such as heart disease, diabetic nephropathy, leg amputation and even early death. Meanwhile, to achieve the recommended diabetes

Disclosure. Authors have no conflict of interests, and the work was not supported or funded by any drug company. management, it is essential for patients to clearly understand the signs and symptoms of the disease and how to properly manage and control diabetes. Health literacy influences important health outcomes, particularly in diabetes management. ${ }^{13}$ Patient health literacy is important and challenging because it requires the individual's awareness and capabilities to understand specific health information. ${ }^{14}$ Literacy has been defined as "an individual's ability to read, write, speak, and compute and solve problems at levels of proficiency necessary to function on the job and in society, to achieve one's goals, and develop one's knowledge and potential". ${ }^{14}$ In particular, patients must have functional health literacy to apply essential knowledge, make decisions, and acquire skills for effective diabetes management. ${ }^{15}$ In contrast, patients with low literacy usually have difficulty in following physician instructions' or have trouble reading medical prescriptions. ${ }^{16}$ Furthermore, chronic illness management and treatment compliance might suffer among patients with low literacy resulting in a low quality of life. ${ }^{16,17}$ Low levels of health literacy appear common among T2DM patients and are significantly associated with less knowledge of self-care management and poorer health outcomes. ${ }^{16-19}$ In the USA, an inadequate level of health literacy was found among 402 patients, and nearly $50 \%$ of these patients lacked knowledge about the importance of lifestyle and dietary factors on glycemic control. ${ }^{18}$ The lack of knowledge among patients with diabetes and its lack of health literacy are considered an obstacle to diabetes self-management. ${ }^{19,20}$ However, there are inconsistent findings with the association of health literacy with self-care management of diabetes. For example, a recent study found an association of low health literacy with low diabetes self-management and poor glycemic control as well as more comorbid conditions. ${ }^{19}$ In Saudi Arabia, it has been reported that misinterpretation of medical instruction is prevalent among patients in hospices. This is because the rate of health illiterate individuals in the country ranges from $13 \%$ to $30 \%$, which possibly related to the privation of education in the Kingdom. ${ }^{21}$ On the other hand, Saudis aged 18 to 40 years old had considerably better health literacy than those aged 41 years old and above, possibly because the younger age group have an advanced degree of educational attainment relative to the older age group. ${ }^{21}$ Furthermore, another study shows that more than 50\% of diabetic patients in Saudi Arabia admit inadequate e-health knowledge, and some of them had trouble interpreting health data published on a website. ${ }^{22}$ 
Meanwhile, a different study revealed no association between glycemic control and functional health literacy. ${ }^{23}$ This inconsistency could be due to factors such as stress, hostility, depression, hopelessness, and other demographic factors that might affect patients' health literacy. ${ }^{24}$ Nevertheless, this association suggests that improving patient health literacy will enable T2DM patients to self-manage their disease and lead to better glycemic control. ${ }^{25}$ The relationship between diabetes self-management and health literacy and depression in Saudi Arabia is unknown. Here we aimed to determine the association and differences between level of health literacy, presence of depressed mood or anhedonia, and their relationships with diabetes self-management among type 2 diabetes mellitus patients in Saudi Arabia.

Methods. This descriptive cross-sectional study was conducted between December 2016 and February 2017 at 2 public tertiary hospitals in Riyadh, Saudi Arabia. To be eligible for the study, patients must have had a confirmed diagnosis of T2DM in their clinical file and be 18 years old or older. Ethical approval was obtained from the local ethics committee, and each hospital selected from the study (E-16-2143). The selected hospitals were chosen because they are considered referral hospitals for patients with T2DM and because the hospitals were easily accessible to the respondents.

A convenience sample of 352 T2DM patients participated in this study. Before distributing the survey questionnaires, consent was obtained from the medical director and head of the nursing department. Before the data gathering began, 2 researchers (trained nurses) explained the purpose of the study to all eligible participants attending the outpatient diabetes clinics. The researchers also seek approval from the physicians to set a time to interact with the patients and distribute the survey questionnaire. The survey questionnaires were distributed as hard copies by the 2 researchers at each hospital under the supervision of one of the authors. The 2 researchers also ensured that written informed consent was obtained for access to the patients' latest clinical records. To ensure confidentiality, the researchers informed all of the participants that they could choose to remain anonymous, that participation was voluntary, and that they had the option to decline to participate at any time or not to complete the survey questionnaire. After providing informed consent, participants were given a four-part survey questionnaire to complete. If the body mass index (BMI) was not available in their clinical records, the researchers measured the participants' height, weight, and waist and hip circumferences to calculate their BMI. Participants reported no problems identified with the questionnaire and it took about 10-15 minutes to complete the survey. No incentives were offered to those who participated in this study.

Instruments and measurement. All eligible participants answered a 4-part self-administered questionnaire that included demographics, information on diabetes self-management, depression, and health literacy. The first part of the questionnaire collected demographic information and clinical characteristics, such as BMI and hemoglobin A1c (HbA1c) (glycated hemoglobin). The second part of the questionnaire was a 16-item Diabetes Self-Management Questionnaire (DSMQ) that measured the self-care management practices (glucose management, dietary control, physical activity, and healthcare use) of the patients. The DSMQ was scored using a Likert-type scale, ranging from zero (does not apply to me) to 3 (applies to me very much). The instrument is a valid instrument used to assess patients' self-care behaviors associated with glycemic control. ${ }^{25}$

The functional health literacy of the participants was assessed using a 36-item Short Test of Functional Health Literacy in Adults (STOFHLA) questionnaire which was translated into Arabic version with the help of a professional language translator. ${ }^{26}$ The instrument was used to analyze functional health literacy scores and categorize scores into adequate (scores 23-36), marginal (scores 17-22), and inadequate (scores 0-17) functional health literacy.

The Patient Health Questionnaire (PHQ-2 English version) was used in this study to assess the presence of depressed mood and anhedonia. ${ }^{27}$ The PHQ-2 is a 2-item questionnaire that is considered the first approach to screen patients for the presence of depressed mood and anhedonia. Patients chose from 4 response options: "not at all", "several days", "more than half the days", and "nearly every day". Patient responses were scored as $0,1,2$, or 3, and the overall score could range from 0 to 6 with higher scores indicating the presence of anhedonia.

The 4-part survey questionnaire was translated by a professional Arabic-English language translator from English to Arabic and back to English. The survey questionnaire was also pilot-tested and modified before the start of data collection.

Statistical analysis. All data were analyzed using the Statistical Package for Social Sciences (SPSS) version 23. Data are presented as frequencies (\%). Age, duration of diabetes, BMI, and other continuous variables 
that are not normally distributed were dichotomized at the median. Furthermore, the PHQ-2 score was dichotomized and recoded into "not depressed" (0-3) and "depressed" (4-6). The Chi-square test was used to analyze the association between 2 categorical variables, and logistic regression analysis was used to identify predictors of depression and predictors of DSM (namely, age, gender, educational attainment). Also we used the Hosmer-Lemeshow to test the goodness-of-fit test or tells how well the data fits the model. P-values of less than 0.05 were considered statistically significant.

Results. Table 1 shows the percentage distribution of the demographic characteristics of the participants. The mean age of the participants was $51.89 \pm 10.94$ years. Of the 352 participants, $37 \%$ of participants were aged $51-60$ years and $87 \%$ of the participants were married. More than half of the participants were males $(50 \%)$, and $42 \%$ of the participants were unemployed. One-third (33\%) of participants held university degrees, and $33 \%$ held tertiary degrees.

Only $17 \%$ of the participants were within a normal weight range, $52 \%$ of the sample were obese (BMI: $\geq 30 \mathrm{kgm}^{2}$ ), and $77 \%$ of the participants had an HbA1c over 7\% (Table 1). With regards to diabetes selfmanagement (DSMQ), the participants had a median score of 39 (range: 7 to 47), indicating high overall diabetes self-management; however, the participants had low to moderate self-care scores with the subscales of 'healthcare - use' $(4.8 \pm 1.2)$ and 'physical activity' $(5.8 \pm 1.1)$. Twenty percent of the participants had a score of 2 or more in the PHQ-2 suggesting the presence of depressed mood or anhedonia. With regards to health literacy, the mean functional literacy score was $16.64(0-36)$ as presented in Table 1 . Nearly half of the participants had low $(50 \%)$ to marginal $(16 \%)$ functional health literacy, while $34 \%$ had adequate health literacy.

Table 2 presents the group comparison between the level of functional health literacy and the sociodemographic, clinical, and psychological factors of the participants. The analysis showed that the majority of the participants had low to marginal functional health literacy. More than $50 \%$ of the participants in the age group of 50 years and above were unemployed, had up to primary schooling, were obese, had PHQ-2 score $\geq 2$, and had low functional health literacy. Surprisingly, low functional health literacy was also found among participants who had a BMI of 18.5 to 24.9 and had a high score of diabetes self-care.
Table 1 - Demographic characteristics of 352 participants.

\begin{tabular}{|c|c|c|}
\hline Characteristic & $\mathrm{n}$ & (\%) \\
\hline Age, years & \multicolumn{2}{|c|}{$51.89 \pm 10.94$} \\
\hline $18-30$ & 12 & $(3.4)$ \\
\hline $31-40$ & 36 & $(10.2)$ \\
\hline $41-50$ & 112 & $(31.8)$ \\
\hline $51-60$ & 129 & $(36.6)$ \\
\hline$\geq 61$ & 63 & $(17.9)$ \\
\hline \multicolumn{3}{|l|}{ Gender } \\
\hline Male & 181 & $(51.4)$ \\
\hline Female & 171 & $(48.6)$ \\
\hline \multicolumn{3}{|l|}{ Marital status } \\
\hline Single & 10 & $(2.8)$ \\
\hline Married & 306 & $(86.9)$ \\
\hline Divorced & 13 & $(3.7)$ \\
\hline Widowed & 22 & (6.9) \\
\hline \multicolumn{3}{|l|}{ Educational level } \\
\hline Non-educated & 36 & $(10.2)$ \\
\hline Primary & 35 & $(9.9)$ \\
\hline Secondary & 84 & $(23.9)$ \\
\hline Tertiary & 116 & $(33.0)$ \\
\hline University & 74 & $(33.0)$ \\
\hline Higher & 7 & $(2.0)$ \\
\hline \multicolumn{3}{|l|}{ Place of work } \\
\hline Government & 92 & $(26.1)$ \\
\hline Private & 31 & $(8.8)$ \\
\hline Retired & 82 & $(23.3)$ \\
\hline Unemployed & 147 & $(41.8)$ \\
\hline \multicolumn{3}{|l|}{ Clinical characteristics } \\
\hline Body mass index $\left(\mathrm{kg} / \mathrm{m}^{2}\right)$ & \multicolumn{2}{|c|}{$31.9 \pm 8.9$} \\
\hline Normal & 59 & $(16.8)$ \\
\hline Overweight & 110 & $(31.3)$ \\
\hline Obese & 183 & $(52.0)$ \\
\hline Hba1c; (range $5.2-14.5$ ) & \multicolumn{2}{|c|}{8.2} \\
\hline $0-6.9$ & 81 & $(23.0)$ \\
\hline$\geq 7$ & 271 & $(77.0)$ \\
\hline$D S M Q($ sum scale $)($ mean $\pm S D)$ & \multicolumn{2}{|c|}{$39.9 \pm 6.5$} \\
\hline Subscale (glucose management) & \multicolumn{2}{|c|}{$7.8 \pm 2.3$} \\
\hline Subscale (dietary control) & \multicolumn{2}{|c|}{$6.5 \pm 1.5$} \\
\hline Subscale (physical activity) & \multicolumn{2}{|c|}{$5.8 \pm 1.1$} \\
\hline Subscale (health-care use) & \multicolumn{2}{|c|}{$4.8 \pm 1.2$} \\
\hline \multicolumn{3}{|l|}{ Level of depressive symptom severity } \\
\hline Not depressed & 279 & $(79.3)$ \\
\hline Depressed & 73 & $(20.7)$ \\
\hline \multicolumn{3}{|l|}{ Health literacy } \\
\hline Low functional health literacy & 175 & $(49.7)$ \\
\hline Marginal functional health literacy & 57 & $(16.2)$ \\
\hline Adequate functional health literacy & 120 & $(34.1)$ \\
\hline
\end{tabular}

More than half (51\%) of those participants who held a bachelor's degree and above had adequate functional health literacy. Age, gender, educational level, employment status, and level of the depressive symptom (PHQ-2) were significantly associated with differences in the level of functional literacy of the participants. 
Table 2 - Difference of functional health literacy levels by participants' characteristics.

\begin{tabular}{|c|c|c|c|c|}
\hline Characteristic & $\begin{array}{l}\text { Low functional } \\
\text { health literacy }\end{array}$ & $\begin{array}{c}\text { Marginal } \\
\text { functional } \\
\text { health literacy }\end{array}$ & $\begin{array}{c}\text { Adequate } \\
\text { functional } \\
\text { health literacy }\end{array}$ & $P$-value \\
\hline \multicolumn{5}{|l|}{ Age, years } \\
\hline Less than 50 & $65(40.6)$ & $29(18.1)$ & $66(41.3)$ & \multirow[t]{2}{*}{0.007} \\
\hline 50 and above & $110(57.3)$ & $28(14.6)$ & $54(28.1)$ & \\
\hline \multicolumn{5}{|l|}{ Gender } \\
\hline Male & $66(36.5)$ & $35(19.3)$ & $80(44.2)$ & \multirow[t]{2}{*}{$<0.001$} \\
\hline Female & $109(63.7)$ & $22(12.9)$ & $40(23.42)$ & \\
\hline \multicolumn{5}{|l|}{ Marital status } \\
\hline Single & $26(56.5)$ & $8(17.4)$ & $12(26.1)$ & \multirow[t]{2}{*}{0.464} \\
\hline Married & $149(48.7)$ & $49(16.0)$ & $108(35.3)$ & \\
\hline \multicolumn{5}{|l|}{ Educational level } \\
\hline Up to primary schooling & $54(76.1)$ & $8(11.3)$ & $9(12.7)$ & \multirow[t]{3}{*}{$<0.001$} \\
\hline Secondary \& tertiary schooling & $93(46.5)$ & $38(19.0)$ & $69(34.5)$ & \\
\hline Bachelor and above schooling & $28(34.6)$ & $11(13.6)$ & $42(51.9)$ & \\
\hline \multicolumn{5}{|l|}{ Place of work } \\
\hline Unemployed & $127(55.5)$ & $34(14.8)$ & $68(29.7)$ & \multirow[b]{2}{*}{0.009} \\
\hline Employed & $48(39.0)$ & $23(18.7)$ & $52(42.3)$ & \\
\hline \multicolumn{5}{|l|}{ Clinical characteristics } \\
\hline \multicolumn{5}{|l|}{ Body mass index } \\
\hline Healthy (BMI of 18.5 to 24.9 ) & $33(55.9)$ & $14(23.7)$ & $12(20.3)$ & \multirow[t]{3}{*}{0.034} \\
\hline Overweight (BMI of 25 to 29.9) & $46(43.8)$ & $13(12.4)$ & $46(43.8)$ & \\
\hline Obese (BMI of 30 or higher) & $93(50.8)$ & $29(15.8)$ & $61(33.3)$ & \\
\hline \multicolumn{5}{|l|}{ Hbalc } \\
\hline (Low > 7\%) & $33(40.7)$ & $18(22.2)$ & $30(37.0)$ & \multirow[t]{2}{*}{0.115} \\
\hline$($ High,$<7 \%)$ & $142(52.4)$ & $39(14.4)$ & $90(33.2)$ & \\
\hline DSMQ 'Sum scale': Low up to 35 & $33(45.8)$ & $14(19.4)$ & $25(34.7)$ & \multirow[t]{2}{*}{0.645} \\
\hline High $36-60$ & $142(50.7)$ & $43(15.4)$ & $95(33.9)$ & \\
\hline \multicolumn{5}{|l|}{ Level of depressive symptom severity } \\
\hline Not depressed & $138(49.5)$ & $39(14.0)$ & $102(36.6)$ & \multirow[t]{2}{*}{0.036} \\
\hline Depressed, n (\%) PHQ-2 score $\geq 2$ & $37(50.7)$ & $18(24.7)$ & $18(24.7)$ & \\
\hline
\end{tabular}

Table 3 - Predictors of low health literacy in type 2 diabetes mellitus (T2DM) patients.

\begin{tabular}{|c|c|c|c|}
\hline Variables & Odd ratio $(95 \% \mathrm{CI})$ & $\begin{array}{l}\text { Std error } \\
(\mathrm{SE})\end{array}$ & $P$-value \\
\hline Age & $0.03(0.33-0.94)$ & 0.26 & 0.030 \\
\hline Gender & $0.48(2.73-0.86)$ & 0.29 & 0.013 \\
\hline $\begin{array}{l}\text { Educational attainment (reference: more than secondary } \\
\text { schooling secondary schooling) }\end{array}$ & & & $<0.001$ \\
\hline Up to primary schooling & $0.33(0.18-0.59)$ & 0.38 & \\
\hline Secondary \& tertiary schooling & $0.16(0.07-0.35)$ & 0.29 & \\
\hline Marital status & $1.27(0.60-2.71)$ & 0.40 & 0.524 \\
\hline Employment status & $1.22(0.70-2.11)$ & 0.27 & 0.467 \\
\hline Body mass index (obese), $\mathrm{n}(\%)$ & $1.24(0.75-2.04)$ & 0.25 & 0.391 \\
\hline Hbalc; (high, <7\%), n (\%) & $0.97(0.55-1.69)$ & 0.28 & 0.920 \\
\hline Level of depressive symptom severity depressed & $0.61(0.32-1.14)$ & 0.32 & 0.126 \\
\hline \multicolumn{4}{|c|}{$\begin{array}{l}\text { Nagelkerke } \mathrm{r}^{2}=0.177 \text {. Hosmer-Lemeshow goodness-of-fit for the model: Chi-square }=11.784, \mathrm{df}=8 \text {, and } \\
p=0.161 \text {. (Nagelkerke } \mathrm{r}^{2} \text {, test the goodness of fit test or tells how well the data fits the model. It scaled from } \\
0 \text { to } 1.0 \text {, the smaller this ratio, the greater the improvement of goodness-of-fit measure) }\end{array}$} \\
\hline
\end{tabular}


Table 4 - Predictors of low diabetes self-management in T2DM patients.

\begin{tabular}{|c|c|c|c|}
\hline Variables & $\begin{array}{l}\text { Odd ratio } \\
(95 \% \mathrm{CI})\end{array}$ & $\begin{array}{l}\text { Std error } \\
\text { (SE) }\end{array}$ & $P$-value \\
\hline Age & $1.05(0.58-1.91)$ & 0.30 & 0.865 \\
\hline Gender & $2.16(1.10-4.24)$ & 0.34 & 0.029 \\
\hline Educational attainment (reference: secondary schooling) & & & 0.681 \\
\hline Up to primary schooling & $1.09(0.56-2.12)$ & 0.33 & \\
\hline More than secondary schooling & $1.49(0.60-3.70)$ & 0.46 & \\
\hline Marital status & $0.96(0.41-2.24)$ & 0.42 & 0.939 \\
\hline Employment status & $0.69(0.37-1.30)$ & 0.32 & 0.258 \\
\hline Body mass index (BMI) (obese), n (\%) & $1.09(0.62-1.90)$ & 0.28 & 0.759 \\
\hline Hbalc; (high, <7\%), n (\%) & $1.19(0.64-2.22)$ & 0.31 & 0.566 \\
\hline Level of depressive symptom severity depressed & $1.87(0.86-4.06)$ & 0.39 & 0.112 \\
\hline \multicolumn{4}{|c|}{$\begin{array}{c}\text { Nagelkerke } p=0.062, \text { Hosmer-Lemeshow goodness-of-fit for the model: } \\
\text { Chi-square }=11.383, \mathrm{df}=8 \text {, and } p=0.181 \text {, (Nagelkerke } \mathrm{R}^{2} \text {, test the goodness of fit test or tells how well } \\
\text { the data fits the model. It scaled from } 0 \text { to } 1.0 \text {, the smaller this ratio, the greater the improvement of } \\
\text { goodness-of-fit measure) }\end{array}$} \\
\hline
\end{tabular}

Table 3 presents the association of factors influencing low health literacy. In the logistic regression analysis, age, gender, and educational attainment emerged as predictors and significant factors of low health literacy. The analysis showed that those participants aged more than 50 years were more likely to have low health literacy (OR 0.03, 95\% CI: 0.33 to 0.94 ). The educational level was also found to have a significant association with the level of functional health literacy of the participants $(p<0.001)$. The model showed that participants with up to primary schooling were more likely to have low health literacy (OR: 3.12, 95\% CI: 1.17 to 8.30), (OR: $0.33,95 \%$ CI: 0.18 to 0.59 ). The analysis also shows that there was a significant relationship between low functional health literacy and the gender of the participants $(p<0.050)$. Table 3 also shows that there was no significant relationship between low functional health literacy and marital status, employment status, body mass index, level of $\mathrm{HbA1c}$, and level of depressive symptoms.

Association of factors influencing low diabetes self-management. The analysis showed that gender was significantly related and strongest predictor to diabetes self-management recording an odds ratio of 2.16 and $p$-value of 0.029 . This indicated that the odds are a lot higher among females than males with diabetes self-management. No significant relationship was found between diabetes self-management and age, educational attainment, marital status, body mass index, level of HbA1c, and level of depressive symptoms of the participant (Table 4).

Discussion. This study highlights the low level of functional health literacy of nearly half of T2DM patients in Saudi Arabia. The low health literacy noted among these T2DM patients is similar to what has been found in the USA and China. ${ }^{28,29}$ Patients who had low health literacy experienced difficulty in obtaining, understanding, and applying health information to enhance their self-management capabilities. ${ }^{30,31}$ Because diabetes requires extensive self-care, it is important that patients understand health information, such as the signs and symptoms of the disease and how to properly manage and control diabetes. On the contrary, a study carried out in Saudi Arabia shows that out of 123 diabetic patients, 93 respondents had sufficient health literacy. ${ }^{21}$ Furthermore, another study conducted in Saudi Arabia found that al though a smaller percentage of the participants had an adequate e-health literacy level, more than half of the total diabetic patients expressed a desire to obtain health knowledge through the Internet, especially the younger generation (between 18 and 40 years old). ${ }^{22}$

Our study showed a significant difference in the levels of functional health literacy with age, gender, educational level, employment status, and level of depressive symptoms of T2DM patients. The results of our study are similar to the results of studies carried out in the USA, in which low health literacy was observed in patients who were older, female, had primary or secondary education or less, and who had diabetes longer. ${ }^{21}$ It is possible that these populations did not fully understand the self-care practices and adherence to medication, as evidenced by the number of patients in this sample who were obese and had an HbAlc over $7 \%$. Given the high number of patients with low functional 
health literacy, it might be valuable for clinicians to consider assessing all their patients' health literacy and to make sure that patients clearly understand the instructions of the physicians about how to carry out diabetes self-management practices.

Interestingly, although the majority of T2DM patients in this sample displayed low to marginal functional health literacy, the findings showed the patients' had high overall DSM-16 scores, which indicated more effective self-care. This might be explained by patients' awareness of the mortality of diabetes, motivating them to adhere to a regiment of self-care. In this study, patients had high overall DSM-16 scores; however, on the subscale of health-care use and physical activity, these T2DM patients had low scores. Specifically, the subscale of health-care use assessed the patient's adherence to (versus avoidance of) appointments with healthcare professionals. The subscale indicated that their adherence to medical appointments was low. The low scores on the subscale of physical activity indicated that the participants skipped physical activity and were not aware of the importance of physical activity in managing diabetes. Studies show that exercise, particularly with regard to diabetes treatment, is effective in improving HbAlc levels and metabolic control. ${ }^{32-34}$ Furthermore, a higher frequency of patient contact with their physicians is associated with better glycemic outcomes. ${ }^{35}$ Our findings suggest that diabetes management education needs to address the discordance in perceptions of patients about diabetes control, particularly about physical activity. Concerning health care use, diabetes management education might be an effective means for health educators to motivate patients to make frequent physician visits for monitoring and to increase patient adherence.

Several studies have addressed the link between health literacy and self-management actions for diabetes control and the findings have been inconsistent. For example, a study in Finland found an association between poor diabetes control among English and Spanish speaking patients and low health literacy. ${ }^{23} \mathrm{~A}$ study carried out in the USA among adults with T2DM found that those who had higher diabetes knowledge scores had higher DSM while those who were highly educated had high health literacy but reported low DSM. ${ }^{24}$ Our present study supported the above results, showing no significant association of health literacy with diabetes self-management. Although low health literacy was found among T2DM patients in this study, it might not necessarily reflect on their self-management actions and practices. A possible recommendation could be proper counseling and recommendation about diabetes control from time to time via reliable sources, such as a dietician or physician.

The major findings of this study are that participants with limited health literacy appeared to practice more diabetes self-management techniques, perhaps because of the awareness of the risks of complications from diabetes. Of note, because of the complexity of diabetes self-management, clinicians, and practitioners should assess their patients' diabetes self-management and monitor their adherence as well as to detect potential patient self-care skills in need of improvement. For example, clinics might need to provide a support system (namely, a visiting nurse) that can monitor and assist patients with diabetes management, particularly with their physical activity. More importantly, further assessments that will use a specific diabetes health literacy scale might provide a clear understanding of determining the association of health literacy on different facets of glycemic control and other aspects of diabetes outcomes.

The authors acknowledge some limitations of the study, such as the small sample size, which means the results cannot be generalized and do not reflect the health literacy and diabetes self-management of T2DM patients in Saudi Arabia. Another limitation was the cross-sectional design of the study; therefore, the reported association of health literacy and diabetes self-management with sociodemographic and clinical characteristics and depression could not establish causality. These findings might help future researchers in the clinical field by establishing a baseline of the level of functional health literacy and diabetes selfmanagement of patients with T2DM in Saudi Arabia. This study might also help as a criteria for comparison for futures studies if it is possible.

In conclusion, the study shows that nearly half of the T2DM patients that exhibited low level of functional health literacy had low diabetes self-management. Notably, the findings show that the level of depressive symptoms severity was not significantly associated with health literacy and diabetes self-management. Age, gender, and educational attainment emerged as predictors and significant factors of low health literacy. Moreover, our findings show that gender significantly affects diabetes self-management in which odds are a lot higher among females than males with diabetes self-management. Finally, we detected no significant association of health literacy with diabetes self- 
management. This study underscores the importance of proper counselling and education about diabetes control on both patients and family members. With appropriate support from family members and counselling of healthcare providers this may engage patients in improving compliance or adherence in facilitating self-care activities and managing their condition.

Acknowledgment. The authors would like to extend their sincere appreciation to the Deanship of Scientific Research, King Saud University, Riyadh, Saudi Arabia for funding this Research group (RG\# 1435-024).

\section{References}

1. Zimmet PZ, Magliano DJ, Herman WH, Shaw JE. Diabetes: a 21 st century challenge. The Lancet Diabetes \& Endocrinology 2014; 2: 56-64.

2. Farsani SF, Van Der Aa MP, Van Der Vorst MMJ, Knibbe CAJ, De Boer A. Global trends in the incidence and prevalence of type 2 diabetes in children and adolescents: a systematic review and evaluation of methodological approaches. Diabetologia 2013; 56: 1471-1488.

3. Saydah SH, Fradkin J, Cowie CC. Poor control of risk factors for vascular disease among adults with previously diagnosed diabetes. JAMA 2004; 291: 335-342.

4. Saaddine JB, Cadwell B, Gregg EW, Engelgau MM, Vinicor F, Imperatore G, Narayan KM. Improvements in diabetes processes of care and intermediate outcomes: United States, 1988-2002. Ann Intern Med 2006; 144: 465-474.

5. Guo XH, Yuan L, Lou QQ, Shen L, Sun ZL, Zhao F, Dai X, Huang J, Yang HY, Chinese Diabetes Education Status Survey Study Group A nationwide survey of diabetes education, selfmanagement and glycemic control in patients with type 2 diabetes in China. Chin Med Journal 2012; 125: 4175-4180.

6. Shi Q, Ostwald SK, Wang S. Improving glycaemic control selfefficacy and glycaemic control behaviour in Chinese patients with type 2 diabetes mellitus: randomised controlled trial. $J$ Clin Nurs 2010; 19: 398-404.

7. Powers MA, Bardsley J, Cypress M. et al., Diabetes selfmanagement education and support in type 2 Diabetes: a joint position statement of the American Diabetes Association, the American Association of Diabetes Educators, and the Academy of Nutrition and Dietetics. Diabetes Educ 2015; 41: 417-430.

8. UK Prospective Diabetes Study (UKPDS) Group, "Intensive blood-glucose control with sulphonylureas or insulin compared with conventional treatment and risk of complications in patients with type 2 diabetes (UKPDS 33). Lancet 1998; 352: 837-853.

9. Onwudiwe NC, Mullins CD, Winston CD et al. Barriers to self-management of diabetes: a qualitative study among low income minority diabetics. Ethn Dis 2011; 21: 27-32.

10. Rotella FE, Mannucci E. Diabetes mellitus as a risk factor for depression. A meta-analysis of longitudinal studies. Diabetes Res Clin Pract 2013; 99: 98-104.

11. Schmitz N, Desch^enes S, Burns R, Smith KJ. Depressive symptoms and glycated hemoglobin A1c: a reciprocal relationship in a prospective cohort study. Psychol Med 2016; 46: $945-955$.
12. Mc Sharry J, Bishop FL, Moss-Morris R, Kendrick T. The chicken and egg thing': cognitive representations and selfmanagement of multimorbidity in people with diabetes and depression. Psychology Health 2013; 28: 103-119.

13. Institute of Medicine of the National Academies. Health literacy: a prescription to end confusion. Washington (DC): National Academies Press; 2004.

14. Health Literacy: report of the Council on Scientific Affairs. Ad Hoc Committee on Health Literacy for the Council on Scientific Affairs, American Medical Association. JAMA 1999; 281: 552-557.

15. Rothman RL, DeWalt DA, Malone R, Bryant B, Shintani A, Crigler B, Weinberger M, Pignone $\mathrm{M}$. Influence of patient literacy on the effectiveness of a primary care-based diabetes disease management program. JAMA 2004; 292: 1711-1716.

16. Rothman R, Malone R, Bryant B, Horlen C, DeWalt D, Pignone $\mathrm{M}$. The relationship between literacy and glycemic control in a diabetes disease management program. Diabetes Educ 2004; 30: 263-273.

17. Williams MV, Baker DW, Parker RM, Nurss JR. Relationship of functional health literacy to patients' knowledge of their chronic disease. A study of patients with hypertension and diabetes. Arch Intern Med 1998; 158: 166-172.

18. Schillinger D, Grumbach K, Piette J, Wang F, Osmond D, Daher C, Palacios J, Sullivan GD, Bindman AB. Association of health literacy with diabetes outcomes. JAMA 2002; 288 : 475-482.

19. Ahola AJ, Groop PH, Barriers to self-management of diabetes. Diabetic Medicine 2013; 30: 413-420.

20. Morris NS, MacLean CD, Littenberg B. Literacy and health outcomes: a cross-sectional study in 1002 adults with diabetes. BMC Family Practice 2006; 7: 49.

21. Alkhaldi TM, Al-Jumaili AA, Alnemer KA, Alharbi K, Al-Akeel ES, Alharbi $\mathrm{MH}$, et. al. Measuring the health literacy level of Arabic speaking population in Saudi Arabia using translated health literacy instruments. Pharmacy Practice 2018; 16: 1223.

22. AlOthman R, Zakaria N, AlBarrak A. Saudi diabetic patients' attitudes towards patient portal use and their perceived e-health literacy. IOS Press 2017; 245: 1211.

23. Al Sayah F, Majumdar SR, Williams B, Robertson S, Johnson JA. Health literacy and health outcomes in diabetes: a systematic review. J Gen Intern Med 2013; 28: 444-452.

24. Poureslami I, Nimmon L, Rootman I, Fitzgerald MJ. Health literacy and chronic disease management: drawing from expert knowledge to set an agenda. Health Promot Int 2016; 32: 743-754.

25. Schmitt A, Gahr A, Hermanns N, Kulzer B, Huber J, Haak T. The Diabetes Self- Management Questionnaire (DSMQ): development and evaluation of an instrument to assess diabetes self-care activities associated with glycaemic control. Health Qual Life Outcomes 2013; 11: 138.

26. National Center for Educational Statistics. National Assessment of Adult Literacy. Washington (DC): National Center for Educational Statistics; 2003.

27. Kroenke K, Spitzer RL, Williams JBW. The patient health questionnaire-2: validity of a two-item depression screener. Med Care 2003; 41: 1284-1292. 
28. Sarkar U, Fisher L, Schillinger D. Is self-efficacy associated with diabetes self-management across race/ethnicity and health literacy? Diabetes Care 2006; 29: 823-829.

29. Tang YH, Pang SM, Chan MF, Yeung GS, Yeung VT. Health literacy, complication awareness, and diabetic control in patients with type 2 diabetes mellitus. J Adv Nurs 2008; 62: 74-83.

30. Bains SS, Egede LE. Associations between health literacy, diabetes knowledge, self-care behaviors, and glycemic control in a low income population with type 2 diabetes. Diabetes Technol Ther 2011; 13: 335-341.

31. Tonoli C, Heyman E, Roelands B, Buyse L, Cheung SS, Berthoin S, Meeusen R. Effects of different types of acute and chronic (training) exercise on glycaemic control in type 1 diabetes mellitus: a meta-analysis. Sports Med 2012; 42: 1059-1080.
32. Boulé NG, Haddad E, Kenny GP, Wells GA, Sigal RJ. Effects of exercise on glycemic control and body mass in type 2 diabetes mellitus: a meta-analysis of controlled clinical trials. JAMA 2001; 286: 1218-1227.

33. Thomas DE, Elliott EJ, Naughton GA. Exercise for type 2 diabetes mellitus. Cochrane Database Syst Rev 2006; 3 CD002968.

34. Parchman ML, Pugh JA, Noël PH, Larme AC. Continuity of care, self-management behaviors, and glucose control in patients with type 2 diabetes. Med Care 2002; 40: 137-144.

35. Sidorenkov G, Voorham J, Haaijer-Ruskamp FM, de Zeeuw D, Denig P. Association Between Performance Measures and Glycemic Control Among Patients With Diabetes in a Community-wide Primary Care Cohort. Med Care 2013; 51: 172-179. 